\title{
Study on response time measurement of distracted driving by virtual reality driving simulator
}

\author{
Sunwoo Kim ${ }^{1}$, Seongsoo Park ${ }^{1}$, Hyowon Jeong ${ }^{1}$ and Junghwan Sung ${ }^{2 *}$ \\ Research Scholar, Department of Media, Soongsil University, Seoul, Korea ${ }^{1}$ \\ Professor, Department of Media, Soongsil University, Seoul, Korea ${ }^{2}$
}

Received: 26-June-2018; Revised: 30-August-2018; Accepted: 12-November-2018

(C2019 Sunwoo Kim et al. Published by ACCENT Social and Welfare Society. This is an open access article distributed under the Creative Commons Attribution (CC BY) License, which permits unrestricted use, distribution, and reproduction in any medium, provided the original work is properly cited.

\begin{abstract}
For safe driving, drivers should always keep their eyes on the road ahead and focus on driving. However, many drivers engage in other activities while driving, such as using mobile phones. The development of information technology and vehicle automation has led to rapid expansion in the control interfaces of automobiles, which in turn has led to increases in incidents of distracted driving. A number of studies have been conducted to measure and inform these risks, among which the visual occlusion test, lane change test, and detection response rate tests are widely used. However, each of these methods has many problems such as the risk of actual vehicle driving and deterioration of immersion due to simulated driving. As an alternative, a virtual reality $(V R)$ driving simulator is proposed. This simulator improves immersion and also includes a method to detect response time by extracting the log data automatically during the driving test. The VR driving simulator proposed in this paper is expected to improve immersion and cost effectiveness of simulated driving. In addition, the VR simulator provides automatic objective data to measure driving distraction and a safe testing environment compared to actual road driving tests.
\end{abstract}

\section{Keywords}

Virtual reality (VR), Distracted driving, Driving simulator, Vehicle automation.

\section{Introduction}

\subsection{Definition of distracted driving}

For safe driving, drivers must look and focus on the road ahead. However, many drivers engage in other activities while driving, such as using a cell phone or eating food. These activities increase the risk of accidents as driving concentration decreases. The importance of vehicle operation is increasing due to the rapid development of information technology and the electrification of automobiles. In the United States, a total of 3,477 deaths and 391,000 injuries were recorded in 2015 due to distracted driving [1]. According to the 2017 traffic safety report of the American automobile association (AAA), two out of three drivers have reported using their cell phones, and one out of three drivers has reported texting while driving [2]. Since these behaviors interfere with safe driving, the National highway traffic safety administration (NHTSA) [3] has defined several types of distracted driving, as listed in Table 1.

\footnotetext{
*Author for correspondence
}

Table 1Three types of distracted driving [4]

\begin{tabular}{|c|c|c|}
\hline Type & Definition & Example \\
\hline $\begin{array}{l}\text { Manual } \\
\text { distraction }\end{array}$ & $\begin{array}{l}\text { To take one or } \\
\text { both hands off } \\
\text { the wheel while } \\
\text { driving }\end{array}$ & $\begin{array}{l}\text { - Eating and drinking } \\
\text { - Smoking } \\
\text { - Adjusting the seatbelt }\end{array}$ \\
\hline $\begin{array}{l}\text { Visual } \\
\text { distraction }\end{array}$ & $\begin{array}{l}\text { Eyes wander off } \\
\text { the road while } \\
\text { driving }\end{array}$ & $\begin{array}{l}\text {-Looking for items on } \\
\text { the floor of the car } \\
\text { - Checking and adjusting } \\
\text { the GPS device } \\
\text {-Changing the radio } \\
\text { frequency }\end{array}$ \\
\hline $\begin{array}{l}\text { Cognitive } \\
\text { distraction }\end{array}$ & $\begin{array}{l}\text { Mind cannot } \\
\text { focus and starts } \\
\text { drifting away }\end{array}$ & $\begin{array}{l}\text {-Talking to another } \\
\text { passenger } \\
\text {-Thinking about } \\
\text { something that is } \\
\text { upsetting }\end{array}$ \\
\hline
\end{tabular}

\section{Study trend}

2.1Recent research on distracted driving Experimental studies through vehicle driving tests are typically performed by automobile manufacturers. However, because of high costs due to the risk of accidents, these studies are mainly managed by 
government agencies or industry associations. As a result, since 2010, the NHTSA has conducted three phases of research to create guidelines for distracted driving [5]. Figure 1 shows an example of guidelines for estimating a distracted driving index based on these studies.

As an alternative to the NHTSA study, researchers at AAA conducted three studies during 2013 (2015 that focused on cognitive workloads. These studies led to the creation of a standard workload rating, as shown in Figure 2. In the first experiment, the researchers defined distraction of a single task that did not involve any additional workload with a rating of one and used the NASA-Task Load Index (TLX) to rate the degree of distraction from performing additional tasks such as listening to the radio (Radio) to the operation span task (OSPAN). The rate of response was assessed through a tactile detection response task (T-DRT) method. In the second experiment, the same methods were used to measure the degree of distraction when recognizing and responding to voice information while driving. The results showed that performing voice interactions using the Siri application on an iPhone while driving could be more dangerous than talking on a handheld mobile phone; the difference between the workload ratings obtained from these tests was four or higher. In the third experiment, 257 drivers of 10 different types of vehicle were surveyed, and the distraction due to voice interaction was measured by the degree of distraction index, which was used to derive the correlation between the type of vehicle and the age of the driver.

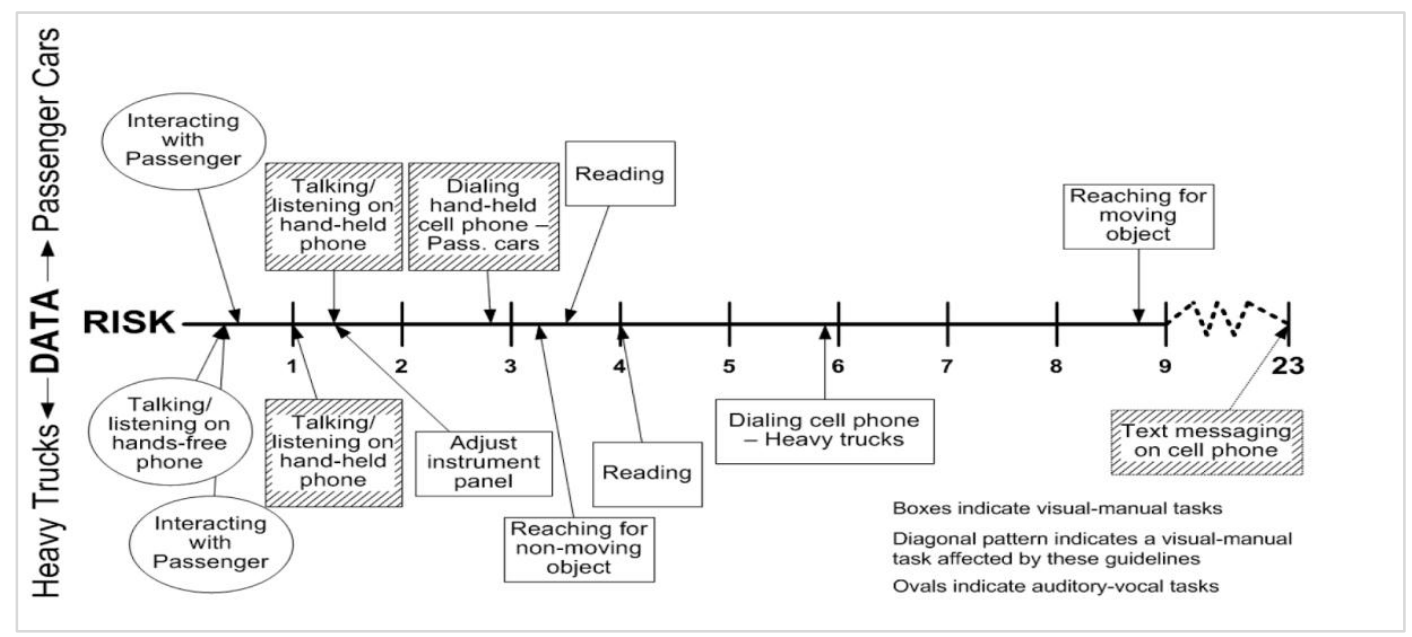

Figure 1 Distracted driving index

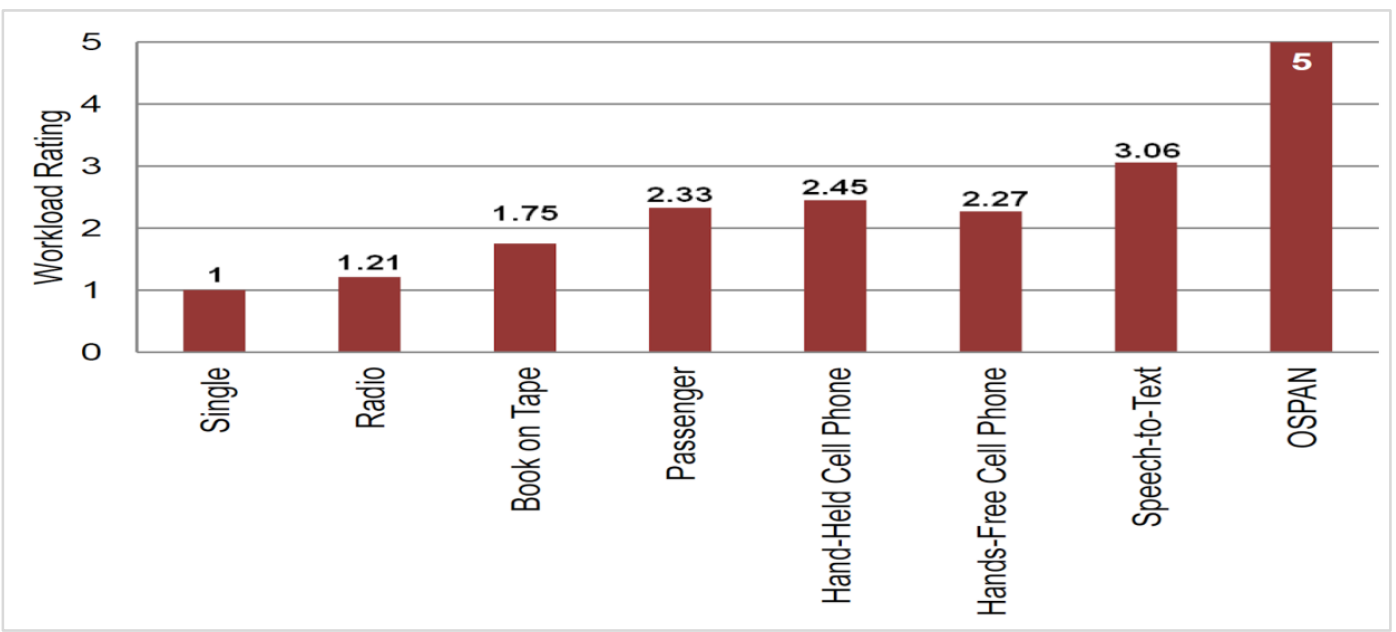

Figure 2 Workload rating while driving based on a AAA study [6] 
2.2Distracted driving test methods

1) Visual occlusion test: This method is listed as an international standard, and is based on the 'glance' phenomenon whereby a driver instantly looks away from the front and gazes elsewhere while performing different actions and driving at the same time. This test is usually conducted without driving. To simulate distracted driving tasks, the participants wear special goggles that are designed to open and close their vision periodically (Figure 3). Researchers control the open (close time period and determine the total shutter open time, which is used to check the completion time of the task against standard criteria [7].

2) Lane change test: This method uses a driving simulator. The simulator has road signs on the left and right at every 150 meters. These signs guide the driver to change to one of three lanes while performing some distracted driving tasks (Figure 4). The task response times and the status of the road signs are monitored [8].

\section{Measurement by the Occlusion Method}

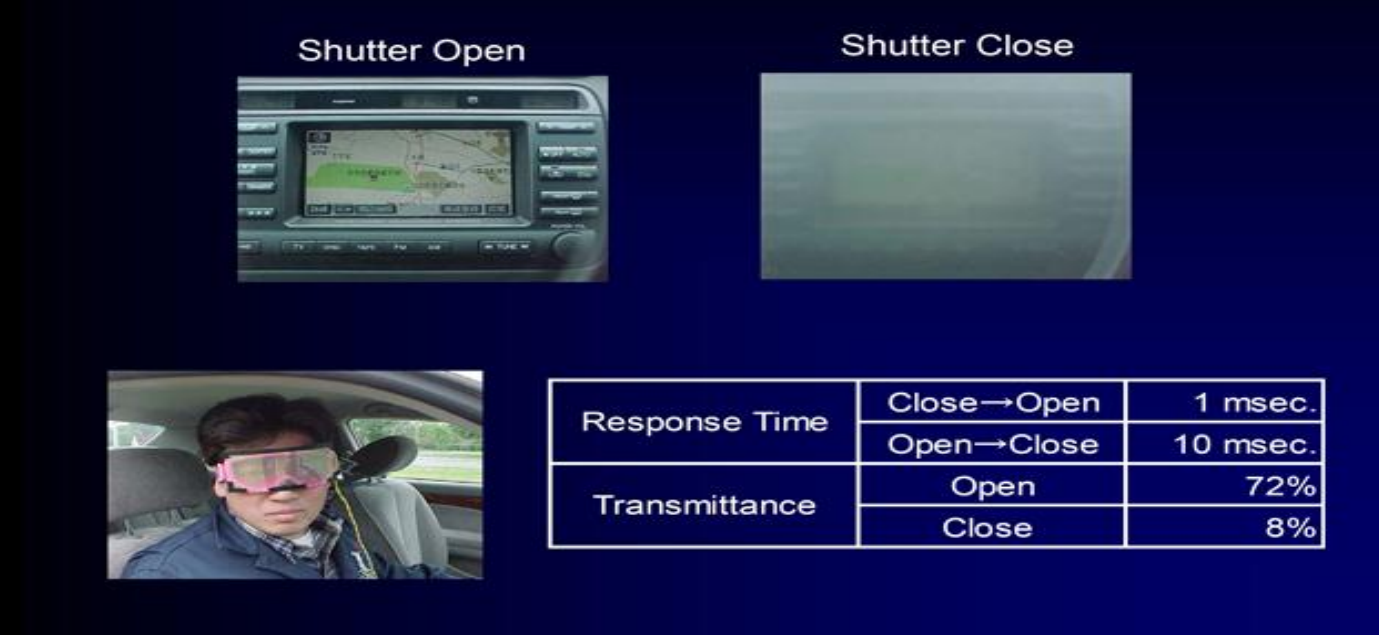

Figure 3 Visual occlusion test method and goggle [9]

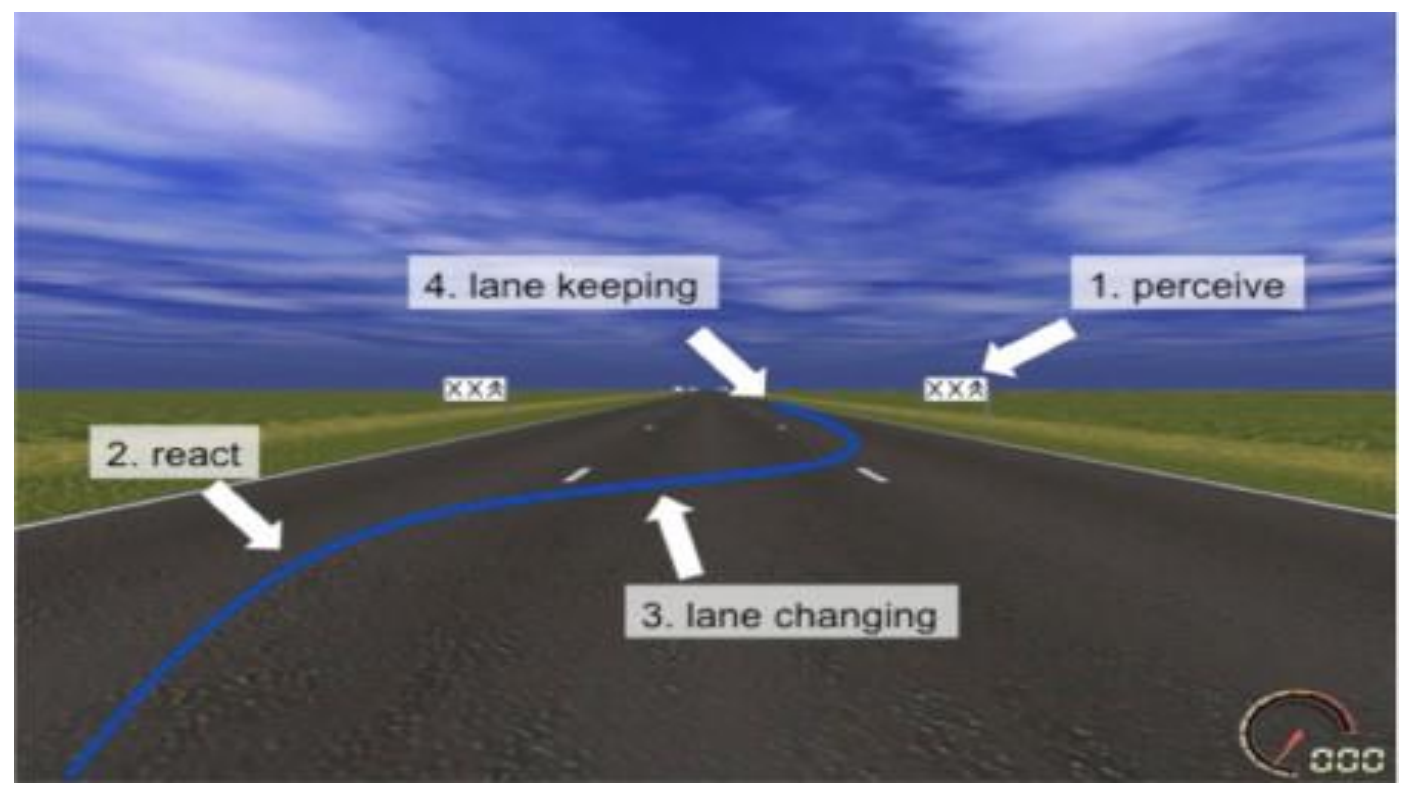

Figure 4 Lane change task simulation screen 
3) Detect response time (DRT): This method may be implemented through actual driving or with a driving simulator. The driver wears a head-mounted device with red and green LED lamps in front, as shown in Figure 5. The driver presses the button on the left or right thumb when the red LED light is on. If the red light is randomly turned on while performing a distracted driving task, the difference in reaction time between the red light turning on and the driver pressing the button is measured [10].


Figure 5 Detect response time test equipment and setup example

4) Eye tracking: This method records the movement of the driver's pupil through an eye tracking device and measures the driver's point of view based on the direction and movement of the pupil (Figure 6). The number of times that a visual distraction occurs is measured by calculating the number of times the eye moves away from the front and the time it takes during additional tasks while driving [11].

Table 2 lists the pros and cons of the distracted driving test methods described in the section. Actual driving tests are the best way to measure driving distraction. However, traffic accidents may occur because the actual road testing could cause drivers to react sensitively to the condition of the road and the driving environment. This method incurs not only a recruiting fee, but also rental and insurance fees. As an alternative, researchers use a method in which a test subject drives on a 3D virtual road in an experimental space with multiple monitors installed. However, this environment can reduce immersion and cause motion sickness due to cognitive dissonance between visual and physical sensations.

As a solution to this problem, some automakers are trying to build a dome-shaped simulator laboratory. Figure 7 shows two examples of simulator laboratories. However, there is a limit to this method because of the high cost of manufacturing and installing the necessary laboratory equipment.

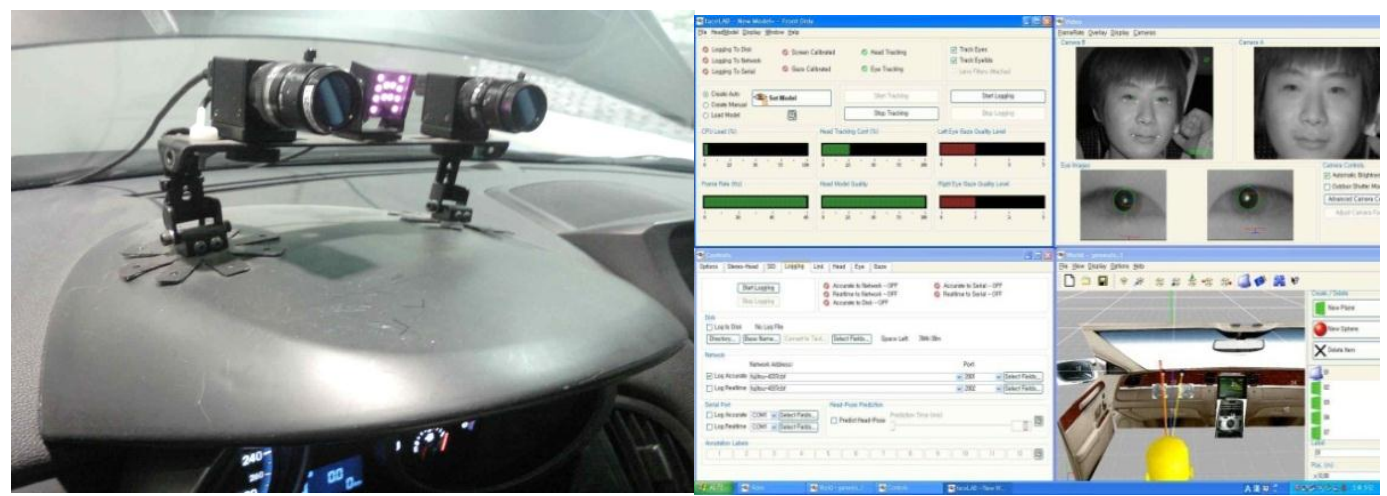

Figure 6 Eye tracking camera and data software (faceLAB)

Table 2 Pros and cons of distracted driving test methods

\begin{tabular}{lll}
\hline Method & Pros & Cons \\
\hline Visual occlusion test & Without driving, low cost & No realism \\
Lane change test & Available in simulator & Low realism \\
Detect response time & Available in real or simulator & Involves wearing equipment \\
Eye tracking & Available in real or simulator & $\begin{array}{l}\text { Needs additional camera, hard to } \\
\text { measure at night }\end{array}$ \\
\hline
\end{tabular}




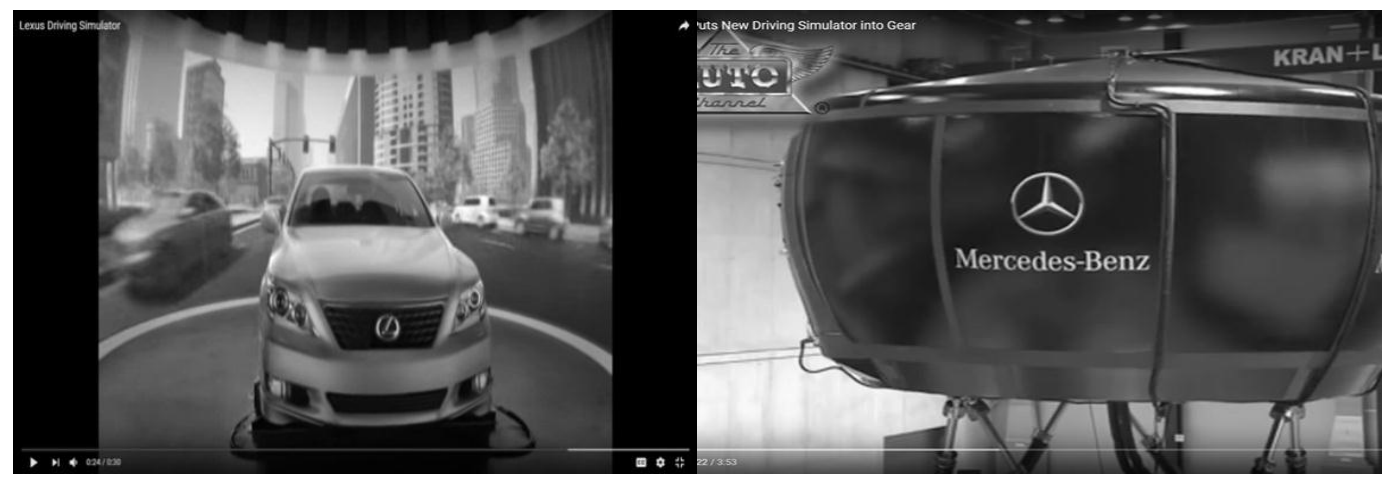

Figure 7 Toyota and Benz's driving simulators

\section{Proposing the virtual reality driving simulator}

3.1Setting up the virtual reality driving simulator environment

1) Hardware: In this study, a driving experiment and measurement using a virtual reality (VR) driving simulator is proposed as an alternative to the less immersive screen-based driving simulator. To improve the realism and immersion, a three-axis moving chair equipped with a Logitech G29 racing wheel and an acceleration-brake pad, an HTC VIVE VR headset, and an in-ear type earphone were installed in the VR simulator environment (Figure 8). In addition, a rotary jog-dial device was developed to allow participants select their desired answers since wearing the VR headset would block their vision and thus impede the performance of touch screen tasks.

2) Software: The virtual roads used in the simulated environment were developed based on the expressway between Seoul and Yangyang (Figure 9). These roads were developed as a driving road data system in which various road alignments such as straight, left turning, right turning, uphill, and downhill were uploaded in real time and unlimited while drivers operate the virtual road. The virtual vehicle was developed based on the Lexus GS350 model, and a virtual display was set up in the test area so that drivers could learn their tasks and select answers from the driving distraction task.

To prevent motion sickness, the chair rotates in the $\mathrm{x}$ axis in accordance with the real-time driving speed. Under these driving conditions, the pitching of the chair produces a diagonal force in the lower back, which is similar to the sum of gravity and the inertia force that acts opposite to the driving direction (Figure 10).

3) Visual and auditory: In this study, a single list of answers are displayed to the driver on a screen (Figure 11). This setting minimizes cyber motion sickness and allows the driver to use the jog-dial to select the desired answer to the questionnaire. In addition, a human voice was extracted to a wav file through the translator TTS (Text To Speech) developed by Google. This translator complements the driver interface with a natural human voice and provides intonation for voice guidance services.



Figure 8 VR driving simulator environment and jog-dial device 

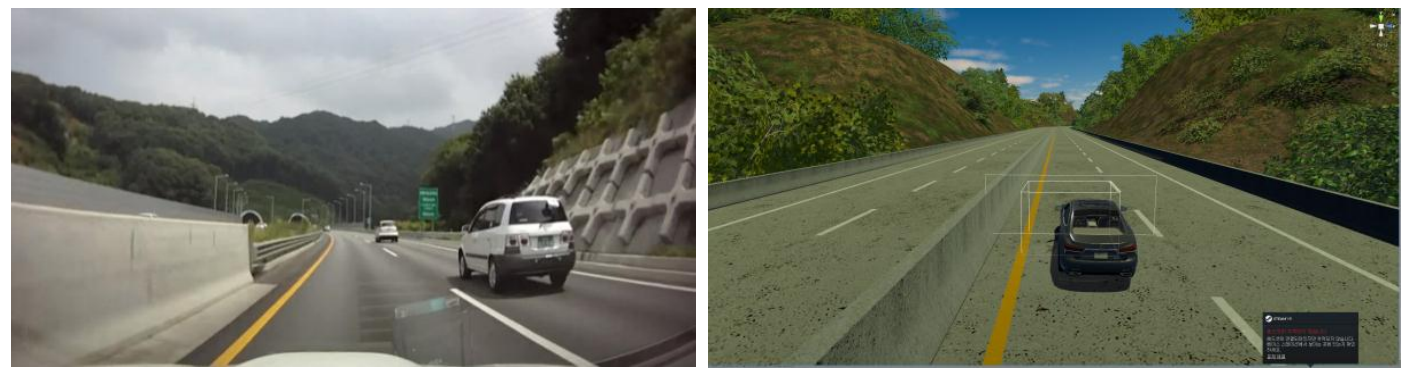

Figure 9 Seoul-Yangyang expressway driving video and test road modeling [12]
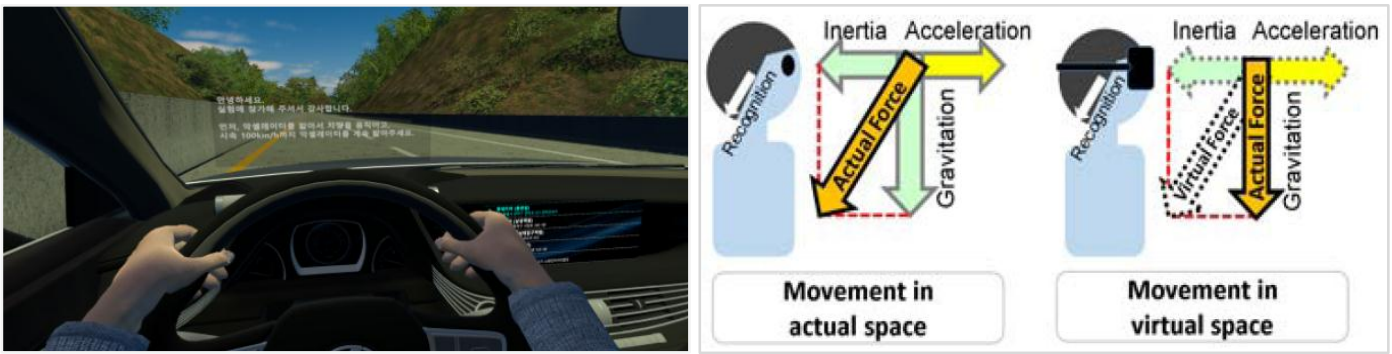

Figure 10 Road and vehicle modeling / force feedback comparison between real and virtual driving [13]
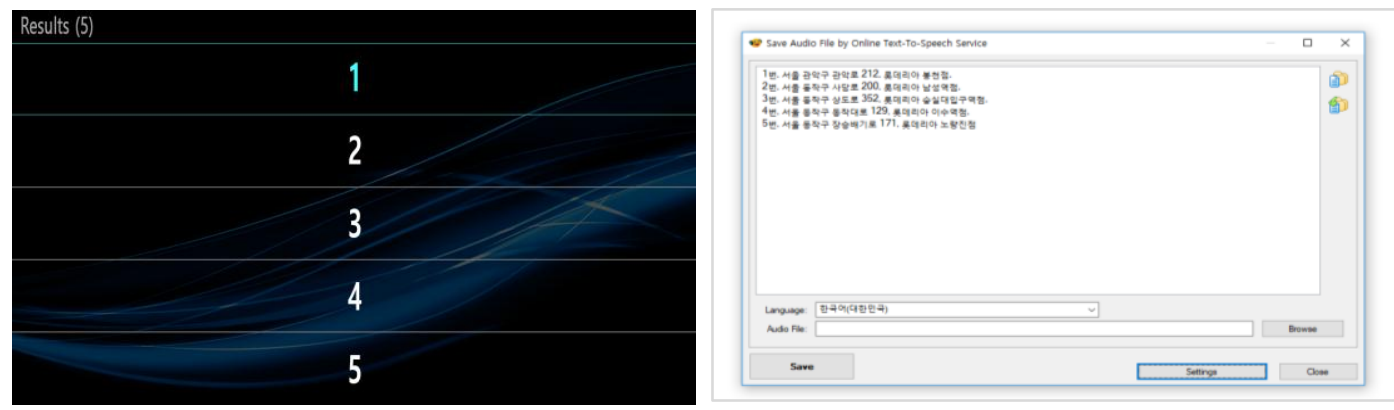

Figure 11 Task selection screen and TTS generator from google translator (Balabolka)

\section{Experimental design using the VR driving simulator}

\subsection{Process and measurement}

The screen of the VR driving simulator shows ten task instructions and questions in sequence to measure the driver's correct answer rate and response time. When the participants select the right answer among five cases, they advance to the next question. If the red dot signal randomly appears on the screen during the test, the participants should turn off the signal by pulling the paddle-shift button located on the left side of the steering wheel. Similar to the DRT method, the driver's reaction time is calculated as the difference between when the red dot appears and when the paddle-shift button is pulled. Figure 12 shows an example of a testing process using the VR simulator.

Even if the participants successfully complete the task within two seconds of the reaction time, the driver is considered to be in an accident if the vehicle in the simulator goes over one-third of the other lane, bumps in the middle wall, or falls off the road (Figure 13). In these cases, two seconds are added to the total response time as a penalty. All work time data are automatically saved according to task number, task type, answer error number, DRT duration, lane over number, road over number, and final duration (Table 3). 




Figure 12 Process for detecting response time test using the VR driving simulator

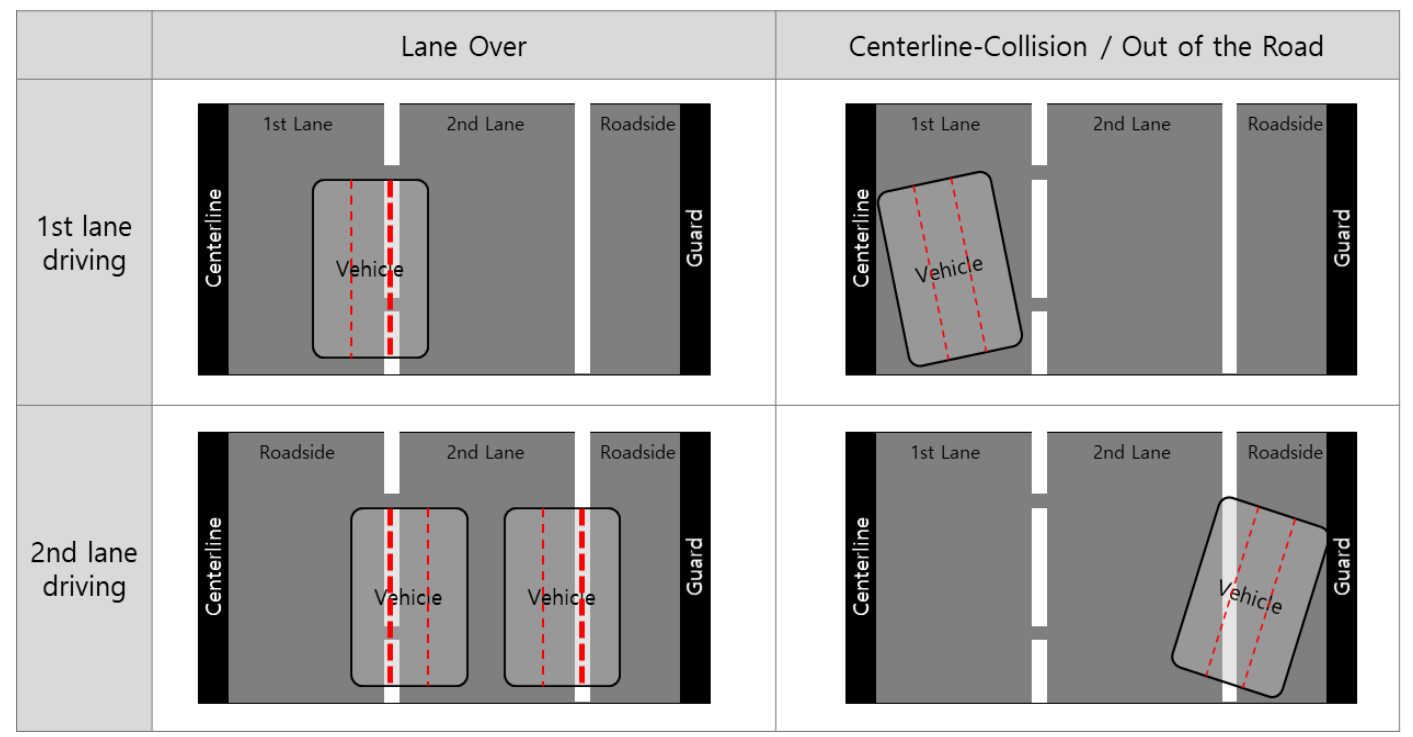

Figure 13 Definition of lane over and out of the road

Table 3 Log data saving template

\begin{tabular}{lllllll}
\hline Task no. & Task type & Error number & DRT duration & Lane over & Road over & Final duration \\
\hline 0 & Multi Words & 2 & 13.889 & 0 & 0 & 13.889 \\
$1-1$ & Single Word & 0 & 2.596 & 1 & 0 & 4.596 \\
\hline
\end{tabular}

\subsection{Test measurement result}

In order to verify the validity of the constructed experimental environment, a total of twenty driver license holders was selected to measure response time twice. First, visual, auditory, and visual and auditory options were presented sequentially so that the driver could select the correct answer that matched the person's name displayed on the center fascia area of the car.

43
The second method allows the driver to select the correct destination displayed on the vehicle in the same way as the first method. As a result of the experiment, it was confirmed that the result automatically calculated through the $\log$ data is extracted and stored in the same form as the designed data template (Table 4). 
Sunwoo Kim et al.

Table 4 Automatically calculated result through log data

\begin{tabular}{|c|c|c|c|c|c|c|c|c|c|}
\hline Participant & $\begin{array}{l}\text { Task } \\
\text { no. }\end{array}$ & Task type & Display type & $\begin{array}{l}\text { Voice } \\
\text { guidance } \\
\text { type }\end{array}$ & $\begin{array}{l}\text { Error } \\
\text { Num }\end{array}$ & $\begin{array}{l}\text { DRT } \\
\text { duration }\end{array}$ & $\begin{array}{l}\text { Lane } \\
\text { over }\end{array}$ & $\begin{array}{l}\text { Road } \\
\text { over }\end{array}$ & $\begin{array}{l}\text { Final } \\
\text { duration }\end{array}$ \\
\hline \multirow[t]{11}{*}{ Choi** } & 0 & Multi Words & Number + Info & Linear & 0 & 1.3 & 1 & 0 & 3.3 \\
\hline & $1-1$ & Single Word & Number + Info & None & 0 & 0.83 & 0 & 0 & 0.83 \\
\hline & $1-2$ & Single Word & Number & Linear & 1 & 0.83 & 0 & 0 & 0.83 \\
\hline & $1-3$ & Single Word & Number & ARS & 1 & 0.78 & 0 & 0 & 0.78 \\
\hline & $1-4$ & Single Word & Number + Info & Linear & 2 & 0.58 & 0 & 0 & 0.58 \\
\hline & $1-5$ & Single Word & Number + Info & ARS & 2 & 0.58 & 0 & 0 & 0.58 \\
\hline & $2-1$ & Multi Words & Number + Info & None & 2 & 0.67 & 0 & 0 & 0.67 \\
\hline & $2-2$ & Multi Words & Number & Linear & 2 & 0.56 & 0 & 0 & 0.56 \\
\hline & $2-3$ & Multi Words & Number & ARS & 0 & 0.63 & 0 & 0 & 0.63 \\
\hline & $2-4$ & Multi Words & Number + Info & Linear & 1 & 0.73 & 3 & 0 & 2.73 \\
\hline & $2-5$ & Multi Words & Number + Info & ARS & 1 & 0.99 & 0 & 0 & 0.99 \\
\hline \multirow[t]{11}{*}{ Hong** } & 0 & Multi Words & Number + Info & Linear & 0 & 0.9 & 0 & 0 & 0.9 \\
\hline & $1-1$ & Single Word & Number + Info & None & 1 & 2.23 & 0 & 0 & 2.23 \\
\hline & $1-2$ & Single Word & Number & Linear & 1 & 1.42 & 0 & 0 & 1.42 \\
\hline & $1-3$ & Single Word & Number & ARS & 1 & 1 & 6 & 0 & 3 \\
\hline & $1-4$ & Single Word & Number + Info & Linear & 3 & 0.49 & 8 & 0 & 2.49 \\
\hline & $1-5$ & Single Word & Number + Info & ARS & 3 & 0.66 & 3 & 0 & 2.66 \\
\hline & $2-1$ & Multi Words & Number + Info & None & 3 & 1.05 & 11 & 0 & 3.05 \\
\hline & $2-2$ & Multi Words & Number & Linear & 4 & 1.49 & 22 & 0 & 3.49 \\
\hline & $2-3$ & Multi Words & Number & ARS & 0 & 1.44 & 25 & 0 & 3.44 \\
\hline & $2-4$ & Multi Words & Number + Info & Linear & 1 & 0.67 & 4 & 0 & 2.67 \\
\hline & $2-5$ & Multi Words & Number + Info & ARS & 0 & 0.73 & 14 & 0 & 2.73 \\
\hline \multirow[t]{5}{*}{ Seong** } & 0 & Multi Words & Number + Info & Linear & 0 & 0.9 & 30 & 0 & 2.9 \\
\hline & $1-1$ & Single Word & Number + Info & None & 1 & 0.94 & 7 & 0 & 2.94 \\
\hline & $1-2$ & Single Word & Number & Linear & 1 & 0.99 & 0 & 0 & 0.99 \\
\hline & $1-3$ & Single Word & Number & ARS & 0 & 1.55 & 0 & 0 & 1.55 \\
\hline & $1-4$ & Single Word & Number + Info & Linear & 1 & 0.76 & 9 & 0 & 2.76 \\
\hline
\end{tabular}

\section{Discussion and conclusion}

Current screen-based driving simulators are difficult to use for continuous experiments because of the lack of realism, less immersive feeling, and the high possibility of motion sickness. However, VR driving simulators can overcome these weaknesses through accurate time, duration, and interactive $\log$ data. Moreover, VR driving simulators provide competitive costs and a safe environment for conducting driving experiments. Finally, VR simulators allow original equipment manufacturers (OEMs) or researchers to define the detailed elements of the experiment before performing actual road tests. Nevertheless, VR driving simulators have some limitations to overcome in order to provide more accurate results. First is the distortion of VR sight, which is very clear in the frontal view, but distorted or blurred in the peripheral view in VR [14]. Second is the rotation force of the steering wheel. Since the G29 steering wheel was originally designed for game entertainment, the wheel diameter is smaller and the rotation angle is larger compared to actual vehicle steering wheels. These hardware issues can be overcome through improved designs. Third is the inability to use a touch screen when participants are wearing the VR headset because their view is blocked and they cannot see and select answers on the touch screen. This problem could be solved by using a gesture-aware glove or an alternative device.

\section{Acknowledgment}

None.

\section{Conflicts of interest}

The authors have no conflicts of interest to declare.

\section{References}

[1] NHTSA, Driver electronic device use in 2015. https://crashstats.nhtsa.dot.gov/Api/Public/ViewPublic ation/812326. Accessed 15 May 2018.

[2] AAA, 2016 Traffic safety culture index (2017).https://aaafoundation.org/2016-traffic-safetyculture-index/. Accessed 20 May 2018.

[3] https://www.nhtsa.gov/risky-driving/distracteddriving. Accessed 26 May 2018.

[4] https://www.dmv.org/distracted-driving/three-typesof-distractions.php. Accessed 26 May 2018. 
[5] https://www.nhtsa.gov/sites/nhtsa.dot.gov/files/distract ion_npfg-02162012.pdf. Accessed 26 May 2018.

[6] Strayer DL, Cooper JM, Turrill J, Coleman J, Medeiros-Ward N, Biondi F. Measuring cognitive distraction in the automobile. 2013.

[7] https://www.iso.org/standard/71508.html. Accessed 20 May 2018.

[8] https://www.iso.org/standard/43361.html. Accessed 20 May 2018.

[9] Asoh T, Ihoshi A. Occlusion method to evaluate visual distraction to be caused by using car navigation systems. In driver metrics workshop. Ottawa, Canada. 2006.

[10] https://www.iso.org/standard/59887.html. Accessed 20 May 2018.

[11] Kim J-H, Kim Y-S, Lee W-S. Real-time monitoring of driver's visual and cognitive distraction. 2011; 2011(5): 1197-202.

[12] https://www.youtube.com/watch?v=dCTDIcdsjsA. Accessed 20 May 2018

[13] Lee HS, Park WJ. A study on method to manipulate to alleviate the simulation sickness of 3D HMD. Journal of Korean Society for Computer Game. 2014; 27(4):85-91.

[14] Han JS, Lee GH. VR tourism content using the HMD device. The Journal of the Korea Contents Association. 2015; 15(3):40-7.



Sunwoo Kim received the Master Degree in Media Engineering from Soongsil University, 2018. $\mathrm{He}$ is working in the Hyundai MOBIS as Principle Research Engineer and Application Occlusion Testing Subject Matter Experts of Car Connectivity Consortium from 2007 to present. His research interests are User Interface, User Experience Research and Interaction Design in the vehicle.

Email: anitooni@gmail.com



Sungsoo Park received the Master Degree in Media Engineering from Soongsil University, 2018. $\mathrm{He}$ is currently a Research Engineer in the VR/AR Research Center, FRONTIS. Inc, Korea.

Email: kawaiipss@crossdesignlab.com



Hyowon Jeong is currently a research scholar in Cross Design Research Lab of Media Department, Soongsil University. Her research interests are Cinematic Movie, Gamification and 3D Interaction Design.

Email: jhw0908@crossdesignlab.com

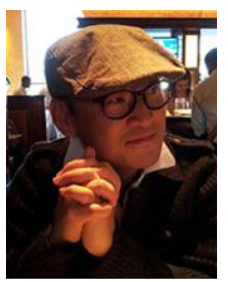

Junghwan Sung received the M.F.A degree in Computer Graphics and Interactive Media from Pratt Institute, U.S.A in 2000 and the Ph.D. degree from the Chung-Ang University, Korea in 2014. His current position is Professor at Media Department, Soongsil University. Her research interests are Digital Art, Digital Storytelling, Interaction Design and Gamification.

Email: artbysung@ssu.ac.kr 